\title{
Introductory Essay
}

Aseem Prakash'

\section{Nonprofit Governance, Public Policy, and the Oxfam Scandal: An Introduction}

\author{
${ }^{1}$ Political Science, University of Washington, 39 Cowen Hall, Seattle 98195, Washington, USA, E-mail: \\ aseem@u.washington.edu
}

DOI: 10.1515/npf-2019-0059

Governance involves creating rules that facilitate actors to work together towards a common goal, ideally in effective and equitable ways. These rules, or institutions, shape incentives actors face (North 1990) and establish the normative environment in which they function. In doing so, institutions outline what behaviors are prescribed, permitted, or prohibited (Ostrom 1990). Consequently, when actors are involved in working collectively, institutions solve coordination and cooperation problems. They do so by outlining what actors are supposed to do and providing assurance that other actors will act upon the same template (March and Olsen 2010). In a nonprofit setting, this means that a well-functioning nonprofit governance system ensures that nonprofits follow specific rules about, say, how to raise or distribute funds. Consequently, stakeholders have the assurance that the nonprofit sector is functioning in the desired ways. In this ideal setting, nonprofits have both the legal and social license to operate (Gunningham, Kagan, and Thornton 2004).

Why do actors not follow the rules? Some suggest that actors disobey rules not because they are acting strategically but because they are either ignorant or the rules are unclear. In this model, education and rule rationalization improve compliance. Others suggest that actors break the rules because they benefit from it.

Actors are often socialized into rules compliance by their normative environment. Here actors face a moral cost and social disapproval for breaking the rules. Further, this environment also shapes their moral compass in a way that compliance becomes their default strategy. Yet, socialization pressures and moral considerations can go only so far. Rule compliance is enhanced when the benefits of rule-breaking are reduced, or the costs of doing so are increased. To accomplish this goal, governance systems incorporate monitoring and enforcement mechanisms to make rule-breaking costly, thereby incentivizing rule compliance. But here again, there are trade-offs because monitoring and enforcement themselves are expensive. Compliance costs not only take up valuable resources but also change the organization's focus on avoiding sanctions as opposed to pursuing its goals. Thus, one of the most profound governance challenges is to figure out the right type and level of monitoring and enforcement the system should provide. While governance gaps are not desirable (Anheier, Hass, and Beller 2013), over-governance poses a problem as well.

Governance systems can and do fail. Rules can be poorly defined. Crafty actors can break the rules, and governance units may fail to monitor and discipline the rule breakers (Prakash and Potoski 2016). Not surprisingly, to a varying degree, governance failure is rampant (North 1990). Governance units - whether located in the government, the for-profit, or the nonprofit sector, do not deliver as promised. To some extent, most systems function quite well with a small level of governance shortfall. But problems arise when such failures, or perceptions of failure, appear to be sizeable, leading to citizen and stakeholder backlash. The organization, or sometimes the sector itself, begins to lose its social license to operate, thereby inviting regulatory, political, and economic sanctions. The Oxfam scandal probably represented this sort of tipping point in terms of stakeholder perception of nonprofit failure.

\section{The Rise of the Nonprofit Sector}

In a landmark article written a quarter-century ago, Lester Salamon declared that the world is experiencing an "associational revolution," comparable in its political and institutional significance to the rise of the nation-state in the nineteenth century. He noted that

Aseem Prakash is the corresponding author

(cc) BY 2019 Prakash published by De Gruyter

This work is licensed under the Creative Commons Attribution 4.o Public License. 
from the developed countries of North America, Europe and Asia to the developing societies of Africa, Latin America and the former Soviet bloc, people are forming associations, foundations and similar institutions to deliver human services, promote grass-roots economic development, prevent environmental degradation, protect civil rights and pursue a thousand other objectives formerly unattended or left to the state (Salamon 1994: 109).

These associations represent the communitarian approach to governance (Etzioni 1998). As per the Tocquevillian ideal, they are community-level, bottom-up endeavors that allow citizens to come together to solve common problems. Putnam (2000) suggests that such local collaborative processes create social capital, which is supposed to foster economic development and democracy.

Nonprofits are associations that provide merit goods and services to the underserved and underprivileged. Scholars view them as correcting both market and state failures (Weisbrod 1975) and suggest that nonprofits are trustworthy because, unlike firms, they are not guided by the profit motive (Hansmann 1980), and unlike the state, they motivate citizens to work towards shared objectives through collaboration as opposed to hierarchical fiats (Keck and Sikkink 1998).

The Tocquevillian nonprofit sector has taken on global proportions. There is now a vibrant global nonprofit sector. Its rise can be traced to both the domestically-oriented "reinventing government" agenda (Osborne 1993) where nonprofits are assigned an important role in the delivery of public services (Salamon and Toepler 2015; Smith and Lipsky 1993) and the internationally-oriented "Washington consensus" (Williamson 1993) which seeks to shrink the state in favor of market-based approaches.

The global nonprofit sector grew for multiple reasons. Donors probably assumed that nonprofits in developing countries with high levels of poverty would find it difficult to raise resources locally. And nonprofits in transitional economies would encounter the Soviet legacy problem because the Soviet system never allowed a truly independent nonprofit sector (Dolšak 2017).

The nonprofit sector also benefited from "aid fatigue" among Western donors who were frustrated with little tangible economic progress in developing countries in spite of providing them billions of dollars of foreign aid. Aid ineffectiveness found an obvious culprit: the governments of aid recipient countries. These were regarded as corrupt, incompetent, and captured by local power structures. In contrast, donors believed that nonprofits had the expertise, grassroots knowledge, and incentives to identify appropriate aid projects and beneficiaries, and the human infrastructure to deliver aid (Edwards and Hulme 1996; Dietrich 2013). Thus, nonprofits got portrayed as the silver bullet to solve social, economic, and political problems.

\section{Governance Failure in the Clobal Charity Sector}

While donors might want to deliver aid through nonprofits, the local nonprofit sector was often underdeveloped. This sort of perceived expertise gap provided the opportunity for international nonprofits to step in. Their presence was supported by citizens who complained about aid wastage but had high regard for the visible international nonprofits. Governments were familiar with them. In some instances, there is a revolving door relationship between international nonprofits and functionaries in governmental and intergovernmental bodies. Thus, global nonprofits emerged as lead actors in a complex aid delivery arrangement. These nonprofits were typically large, complex, professionally-managed, and bureaucratized organizations, and not the small, nimble, community-based ones that the nonprofit mythology had imagined.

In the global nonprofit chain (Burger, Owen, and Prakash 2018), donors work with a prominent international nonprofit to execute a specific project in the aid recipient country. This could be a development project or a disaster relief project (in Haiti, Oxfam was administering disaster relief). For example, Haiti's 2010 earthquake led to a sizeable infusion of foreign funding for rebuilding. But this has also attracted a large number of international nonprofits, such as Oxfam, turning it into the "Republic of NGOs." (Kristoff and Panarelli 2010). As per the recent Global Humanitarian Assistance Report (Development Initiative 2018: 73), 85 \% of humanitarian assistance in 2016 was funneled via international nonprofits. Of this, over half (53\%) went to the ten largest nonprofits, with local and national NGOs receiving just $1.5 \%$ of the direct funding.

While in recent years, some mid to large size international nonprofits have adopted confederated organizational forms with affiliates or chapters in the global south, many still do not have boots on the ground. Instead, these global actors employ local nonprofits to deliver aid. But this arrangement has created resource and power asymmetries between international nonprofits and their local constituents (Hearn 2007; Ahmad 2007). Whereas nonprofits are supposed to be non-hierarchical and horizontally networked (Keck and Sikkink 1998), global nonprofit chains embody hierarchical patron-client ties between Western donors and their local contractors (Chahim and Prakash 2014). 
The Oxfam scandal illustrates the above problems. Oxfam is renowned for its humanitarian and development work. It has enormous moral authority and is at the forefront of advocating for humanitarian causes, including highlighting the issues of inequality. In February 2018, a media report suggested that Oxfam covered up the sexual misconduct of its staff in Haiti, where it was providing earthquake relief and humanitarian aid. As the Haiti scandal has unfolded, similar allegations have surfaced regarding its overseas staff in countries such as Chad and Southern Sudan.

Oxfam saw its social and regulatory license to operate slipping away. The UK's Charity Commission opened a formal inquiry, donations from individual donors plummeted (at least in the short run), corporations withdrew their support, the UK government and the European Commission threatened to withdraw funding and celebrity brand ambassadors such as Minnie Driver resigned. Media, both traditional and social, also highlighted similar governance failures in the British charity sector (Scurlow, Dolsak, and Prakash 2020). In 2017 alone, more than 120 workers in leading British charities, including Save the Children, Christian Aid, and the British Red Cross, were accused of sexual abuse. ${ }^{1}$

The Oxfam and other nonprofit scandals raise important questions as to why principled nonprofits behave in unprincipled ways. Nonprofits are supposed to correct governance failures, not embody them. One argument is that governance failure is rooted in the lack of institutional oversight over internal operations, both by internal bureaucratic structures and external monitors (Prakash and Gugerty 2010). This oversight deficit is problematic, given the power asymmetries between nonprofit managers and the local actors they employ.

But why this administrative neglect? Structurally, because governmental and inter-governmental funding is an important component of their budgets, nonprofits tend to focus on managing their external environment. They tend to focus on financial reporting and underemphasize other performance indicators (Phillips 2013). Importantly, they neglect internal governance, which allows nonprofit managers to abuse their power over local subordinates and the local community (Bruno-van Vijfeijken 2018). The gender composition of the leadership structure is particularly galling. The \#FairShare initiative notes that although "women make up nearly $70 \%$ of the global social impact workforce, they hold less than $30 \%$ of the top leadership positions." ${ }^{2}$

The insistence on nonprofit virtue sometimes encourages scholars and practitioners to ignore the possibility of perverse organizational dynamics and managerial abuse within nonprofits. Indeed, Salamon (1994) recognized the "myth of pure virtue." As he noted, nonprofits are organizations with dysfunctionalities that afflict any large bureaucracy. It is these sorts of dysfunctionalities that have led to Oxfam-type scandals that seem to be afflicting the global nonprofit sector.

\section{Structure of This Symposium Issue}

This symposium issue emerged from a roundtable on "Oxfam: Lessons for Nonprofit Theory and Governance" that my colleagues and I had organized at the 2018 ARNOVA annual conference. After the roundtable, we were approached by several individuals inquiring whether this roundtable could be part of a journal symposium or an edited volume. After the conference, we approached Dennis Young, editor-in-chief of Nonprofit Policy Forum, with a proposal for a special issue. Dennis graciously agreed and we then collectively embarked on this exciting project.

This symposium issue features four papers by distinguished scholars and policy practitioners. The authors implicitly agreed on a division of labor so that their respective papers intentionally focused on a specific dimension of nonprofit governance failure. The first paper, "Putting Humpty Together Again: How Reputation Regulation Fails the Charitable Sector," by Susan Phillips, examines how problems of the regulatory environment encouraged nonprofit failure. In particular, the emphasis on the "principled actor" narrative incentivizes nonprofit management to give high priority to reputation management. On the one hand, nonprofits must compete for grants and donations. On the other hand, they are expected to function with low overheads, which allow governance gaps to emerge within the organization. The paper also notes that nonprofit regulators often lack resources to carry out their oversight functions. Further, regulators often do not get actionable information from the reports that nonprofits are required to turn in. The paper notes that given the global nature of the nonprofit industry, there needs to be a system of regulatory coordination across countries. This is an important issue because the regulation of the nonprofit sector tends to be idiosyncratic, often reflecting the historical origins of the sector in a given country. But this sort of regulatory heterogeneity creates enormous challenges for collecting comparable information to regulate the cross-border activities of any actor. The Oxfam scandal is a product of both a regulatory failure and an overemphasis on reputation management, which incentivizes nonprofits to be less transparent about internal governance failures.

The second paper, "Policy Neglect: The True Challenge to the Nonprofit Sector", by Helmut Anheier and Stefan Toepler notes the complexity of the relationship between governments and nonprofits across space and 
also over time. In the last two decades, a large number of countries have enacted laws that impose restrictions on how nonprofits acquire and spend resources. However, the core problem the nonprofit sector faces is policy neglect in fulfilling its roles as a service provider, cohesion builder, and social innovator. The paper acknowledges that the nonprofit sector suffers from regulatory voids (an issue raised by Susan Philips as well), which erodes public trust in the sector. The paper calls for a more nuanced and differentiated regulatory and policy approach that governments must adopt for the nonprofit sector. As of now, there is a tendency to have an overarching regulatory and policy approach that does not take into account the different roles nonprofits play and the different regulatory and policy issues they confront.

Could the governance problems confronting the nonprofit sector be addressed by superior regulation? Or, do these problems reflect a deep-rooted structural issue of patriarchy? The virtue narrative suggests that nonprofits solve societal failures. Because they are principled and moral, nonprofits are not affected by deep-seated societal problems such as patriarchy. The third paper" \#Metoo/\#Aidtoo and Creating an Intersectional Feminist NPO/NGO Sector", by Elizabeth, Gillespie, Roseanne Mirabella, and Angela Eikenberry, challenges the virtue narrative and recognizes that nonprofits function in a structural context marked by power asymmetries. Not surprisingly, sexual violence, which reflects deep-seated power asymmetries, is pervasive in the global humanitarian sector (Eikenberry and Mirabella 2020). The extent of this problem is so severe that women working in this sector have launched the \#aidtoo movement to highlight this issue. The paper contends that scandals such as Oxfam should not be dismissed as cases of regulatory voids that can be corrected by more and better regulation. It calls for leadership change because, in most nonprofits, bureaucratic power resides with men, who exercise control over their subordinates, typically women. Thus, instead of persisting with the principled actor narrative and blaming Oxfam-type scandals on regulatory voids, the authors argue for a feminist lens to examine the power structures and norms of patriarchy which pervade the society and nonprofits alike.

The fourth paper, "Culture is what you see when compliance is not in the room: Organizational culture as an explanatory factor in analyzing recent INGO Scandals", by Tosca Bruno-van Vijfeijken, raises important issues about the role of organizational culture in facilitating governance failure. The paper suggests that the disconnect between the 'espoused' and 'real, in-practice' shapes the behaviors of NGO staff. In particular, because nonprofits are often tasked with delivering products in times of extreme stress and emergency, these organizations tend to have a high level of internal solidarity. Yet, this sort of close bonding also discourages individuals from speaking out against a toxic workplace environment. Furthermore, insistence on the virtue narrative means that problems within the organization are shrugged off as aberrations, and not seen as instances of systematic governance failure. Thus, nonprofits must develop a culture of internal transparency where toxic behaviors are challenged and criticized. In doing so, it speaks to the Eikenberry et al. paper, which also focuses on internal failure but attributes it to deep-seated patriarchal values. For Eikenberry et al. nonprofits reproduce the societal norms within. For Bruno-van Vijfeijken, the task environment leads nonprofits to overlook the toxic culture that allows for abuse.

To conclude, the dramatic worldwide growth of nonprofits since the end of the cold war was not a bottomup phenomenon. Instead, this proliferation has been largely due to financial and political support from overseas donors and multilateral agencies (Reimann 2006). Unfortunately, this funding model and the virtue narrative that dominates the thinking about nonprofits, have contributed to lax governance both within and outside the nonprofit sector. Media exposés about Oxfam, Save the Children, The Nature Conservancy, and Mercy Corps, have highlighted that the status quo is not acceptable. Nonprofits will need to identify and then correct governance failures urgently lest their regulatory and social license to operate is compromised further. Further, all nonprofits must ask fundamental questions about power asymmetries that might be afflicting the relationship within nonprofits, and between nonprofits and their stakeholders. This symposium has highlighted factors that have contributed to this pervasive nonprofit failure and identified strategies for how this sector could reform.

\section{Notes}

1 https://www.christianpost.com/news/christian-aid-save-the-children-among-charities-caught-in-sex-scandals-pedophile-warningin-sector.html

2 https://www.fairsharewl.org/

\section{References}

Ahmad, M. 2007. “The Careers of NCOs Field-Workers in Bangladesh.” Nonprofit Management \& Leadership 17: 349-65. 
Anheier, H. K., R. Hass, and A. Beller. 2013. “Accountability and Transparency in the Cerman Nonprofit Sector: A Paradox?" International Review of Public Administration 18 (3): 69-84.

Bruno-van Vijfeijken, T. 2018. Internal Democracy within Transnationally Operating Non-governmental Organisations: Are We as Democratic as We Think? Annual Report on the State of Civil Society. CIVICUS.

Burger, R., T. Owen, and A. Prakash. 2018. "Clobal Nonprofit Chains and the Challenges of Development Aid Contracting." Nonprofit Policy Forum 9 (4): 1-14.

Chahim, D., and A. Prakash. 2014. “NGOization, Foreign Funding, and the Nicaraguan Civil Society.” Voluntas 25 (2): 487-513.

Development Initiative. 2018. Clobal Humanitarian Assistance Report, 2017. http://devinit.org/post/global-humanitarian-assistance-2017/

Dietrich, S. 2013. “Bypass or Engage? Explaining Donor Delivery Tactics in Foreign Aid Allocation.” International Studies Quarterly 57 (4): 698 712.

Dolšak, N. 2017. "Bowling Together: Mobilization of Collective Action by Environmental NCOs." Nonprofit Policy Forum 8 (1): $25-44$.

Edwards, M., and D. Hulme. 1996. “Too Close for Comfort? the Impact of Official Aid on Nongovernmental Organizations." World Development 24: 961-73.

Eikenberry, A. M., and R. M. Mirabella. 2020. “Nonprofit/Nongovernmental Organization Sexual Corruption: A Critical Feminist Perspective." In Clobal Corruption and Ethics Management: Translating Theory into Action, edited by Carole L. Jurkiewicz, 26-33. Rowman \& Littlefield.

Etzioni, A. 1998. The New Golden Rule: Community and Morality in a Democratic Society. New York: Basic Book.

Cunningham, N., R. A. Kagan, and D. Thornton. 2004. “Social License and Environmental Protection: Why Businesses Co beyond Compliance." Law \& Social Inquiry 29 (2): 307-41.

Hansmann, H. B. 1980. “The Role of Nonprofit Enterprise.” The Yale Law Journal 89 (5): 835-901.

Hearn, J. 2007. “African NCOs: The New Compradors?" Development and Change 38 (6): 1095-110.

Keck, M., and K. Sikkink. 1998. Activists beyond Borders. Ithaca, NY: Cornell University Press.

Kristoff, M., and L. Panarelli. 2010. Haiti: A Republic of NCOs? Peace Brief 23. Washington, DC: United States Institute of Peace.

March, J., and J. Olsen. 2010. Rediscovering Institutions. New York: Simon and Schuster.

North, D. C. 1990. Institutions, Institutional Change, and Economic Performance. Cambridge: Cambridge University Press.

Osborne, D. 1993. “Reinventing Government.” Public Productivity \& Management Review July (16): 349-56.

Ostrom, E. 1990. Coverning the Commons. Cambridge, UK: Cambridge University Press.

Phillips, S. D. 2013. “Shining Light on Charities or Looking in the Wrong Place? Regulation-by-transparency in Canada." Voluntas 24 (3): $881-$ 905.

Prakash, A., and MK. Gugerty. 2010. “Trust but Verify? Voluntary Regulation Programs in the Nonprofit Sector.” Regulation \& Covernance 4 (1): 22-47.

Prakash, A., and M. Potoski. 2016. “Dysfunctional Institutions? toward a New Agenda in Covernance Studies.” Regulation \& Covernance 10 (2): $115-25$.

Putnam, R. D. 2000. Bowling Alone: The Collapse and Revival of American Community. New York: Simon and schuster.

Reimann, K. D. 2006. “A View from the Top: International Politics, Norms and the Worldwide Growth of NCOs." International Studies Quarterly 50 (1): 45-68.

Salamon, Lester M. 1994. “The Rise of the Nonprofit Sector." Foreign Affairs 73 (4): 109-22.

Salamon, L. M., and S. Toepler. 2015. “Covernment-Nonprofit Cooperation: Anomaly or Necessity?” Voluntas: International Journal of Voluntary and Nonprofit Organizations 26 (6): 2155-77.

Scurlow, R., N. Dolsak, and A. Prakash. 2020. “Recovering from Scandals: Twitter Coverage of Oxfam and Save the Children Scandals." Voluntas. forthcoming.

Smith, S. R., and M. Lipsky. 1993. Nonprofits for Hire. Cambridge, MA: Harvard University Press.

Weisbrod, B. A. 1975. "Toward a Theory of the Voluntary Nonprofit Sector in a Three Sector Economy." In Altruism, Morality, and Economic Theory, edited by Edmund S. Phelps. New York: Russell Sage Foundation.

Williamson, J. 1993. “Democracy and the "Washington consensus"." World Development 21 (8): 1329-36. 